\title{
Diagnosis of Placenta Accreta by Uterine Artery Doppler Velicometry in Patients with Placenta Previa

\author{
Ibrahim Mahrous Kandil ${ }^{1}$, Mohamed Ali Mohamed ${ }^{1}$, Ahmed Mohamed Taha ${ }^{2}$ \\ ${ }^{2}$ Obstetrics \&Gynecology Department, Beni-Suef General Hospital, Ministry of Health, Egypt
} \\ ${ }^{1}$ Obstetrics \& Gynecology Department, Faculty of Medicine, Al-Azhar University, Egypt
}

\begin{abstract}
Background: Placenta accreta occurs in the complete or partial absence of the decidua basalis. Women with previous cesarean delivery or placenta previa are known to be at greater risk of placenta accreta.

Objectives: to evaluate ultrasound accuracy in diagnosing placenta accreta and its variants and to detect the potential value of uterine artery Doppler in diagnosing placenta accreta and to assess the impact of antenatal diagnosis in Egyptian population.

Patients and Methods: This prospective study was conducted on (100) pregnant women diagnosed as placenta previa by ultrasonography and were candidates for either emergency or elective repeated CS or hysterectomy (if the diagnosis of placenta accreta is confirmed). All these patients were randomly selected from the Obstetrics Clinic at Beni-Suef General Hospital during their 3rd trimester. The study was approved by the medical ethics committee of Al-Azhar University academic and ethical committee and a written informed consent was obtained from all patients.

Results: The results obtained from this study indicated no statistically significant differences regarding the mean values of uterine artery Doppler PI and RI between cases of placenta accreta and non accreta ( $\mathrm{p}$ value $=.078 \& 0.58$ respectively) in correlation with histopathological assessment. Our results showed no statistically significant correlation regarding mean values of uterine artery Doppler PI and RI between cases of placenta accreta and placenta non accreta ( $\mathrm{p}$ values $=0.341,0.953$ respectively) in correlation with intra-operative assessment.

Conclusion: Several ultrasound criteria can be used in diagnosis of placenta accreta, as this study showed their high accuracy. They include loss of retroplacental clear zone, presence of abnormal placental lacunae, myometrial thinning and utero-vesical hypervascularity. On the other hand, both loss of retroplacental clear zone, abnormal placental lacunae can predict which patient will mostly have CS hysterectomy.
\end{abstract}

Keywords: Uterine Artery Doppler, Placenta Accreta.

\section{INTRODUCTION}

Placental attachment disorder (PAD) or Morbidly Adherent Placenta (MAP) or the most recent synonym Abnormally Invasive Placenta (AIP) encompasses a spectrum of conditions characterized by abnormal adherence of the placenta to the implantation site. It can be classified according to their degree of trophoblastic invasion through the myometrium and the uterine serosa into placenta accreta, increta and percreta ${ }^{(1)}$.

Morbidly adherent placenta (MAP) is generally associated with excess blood loss, bladder injuries and hysterectomies and its incidence has increased significantly over the last 50 years ${ }^{(2)}$.

Maternal mortality from placenta accreta is estimated to be 6-7\% regardless of the type of the operation ${ }^{(3)}$.

Despite the modern advances in imaging techniques, no single diagnostic method affords complete assurance for the presence or absence of placenta accreta ${ }^{(4)}$.

Antenatal diagnosis of MAP and multidisciplinary team approach has the potential of reducing maternal and fetal intrapartum complications. This includes less maternal blood loss, with fewer transfusion requirements, reduction of hysterectomy rate as well as intra operative urologic and gastrointestinal injuries and maternal deaths ${ }^{(5)}$.

The safe use of transvaginal ultrasound in cases of placenta previa has been confirmed and it has been found that transvaginal ultrasonography is superior to transabdominal sonography in the diagnosis of placenta previa and invariably correct in ruling it out ${ }^{(6)}$.

Trans-abdominal ultrasound and trans-vaginal ultrasound are complementary for diagnosis. Also, transvaginal ultrasound is safe in cases of placenta previa and allows complete examination of the lower uterine segment ${ }^{(7)}$.

The 'European Working Group on Abnormally Invasive Placenta' (EW-AIP) is an international nonprofit group consisting of 29 obstetricians, gynecologists, pathologists and anesthesiologists and basic science researchers from 11 European countries. The aim of the group is to advance diagnosis and treatment and to promote research and knowledge on AIP in order to improve comparability of future studies, to increase diagnostic capabilities and to facilitate international collaboration; the EW-AIP here proposes standardized definitions of the AIP imaging descriptors they are established and published in the "American Journal of Obstetrics and Gynecology" in $2016^{(8)}$.

\section{PATIENTS AND METHODS}

A total of randomly chosen 100 women with placenta previa were enrolled prospectively at Obstetrics Clinic at Beni-suef General Hospital during their follow up visits in the 2nd and 3rd trimesters and underwent ultrasound examination by expert ultra-sonographer. 
The ult1rasound diagnosis (2D grayscale and color Doppler) of placenta accreta was based on the detection of the following: loss of the retroplacental clear zone, presence of abnormal placental lacunae, bladder wall interruption, placental bulge, myometrial thickness $<1$ $\mathrm{mm}$, utero-vesical hypervascularity and bridging vessels, uterine artery Doppler was done for all cases enrolled in this study.

Definitive diagnosis was made at delivery by Cesarean section. Maternal outcome in cases diagnosed antenatal was compared with that in cases diagnosed at delivery and the patient underwent CS hysterectomy, specimen was sent for histopathological confirmation of the diagnosis of placenta accreta.

\section{Ethical approval and written informed consent :}

The study was approved by the medical ethics committee of Al-Azhar University academic and ethical committee and a written informed consent was obtained from all patients.

\section{Inclusion criteria:}

- Maternal age from 20 to 45 years.

- Gestational age $>28$ weeks, confirmed by the first day of the last menstrual period or first trimesteric ultrasound.

- Normal spontaneous onset of puberty and normal sexual development.

- Single living fetus.

- One or more cesarean section or hysterotomy.

- Placenta previa (all grades) with high possibility of morbidly adherent placenta accreta (all types).

\section{Exclusion criteria:}

- Maternal chronic medical disorder (diabetes mellitus or hypertension).

- Pregnancy induced disorders (pre-eclampsia or gestational diabetes).

- Associated fetal anomalies.

The patients were divided into 2 study groups:

Group A: Placenta Accreta Group $(\mathrm{n}=51)$ : included patients with placenta previa with invasion.

Group B: Placenta non Accreta Group $(n=49)$ : included patients with placenta previa without invasion.

\section{Statistical analysis}

The recorded data were analyzed using the statistical package for social sciences, version 20.0 (SPSS Inc.,
Chicago, Illinois, USA). Quantitative data were expressed as mean \pm standard deviation (SD). Qualitative data were expressed as frequency and percentage.

\section{The following tests were done:}

- Independent-samples t-test of significance was used when comparing between two means.

- Chi-square $\left(\mathrm{x}^{2}\right)$ test of significance was used in order to compare proportions between two qualitative parameters.

- The confidence interval was set to $95 \%$ and the margin of error accepted was set to 5\%. The p-value was considered significant as the following:

- Probability (P-value)

- P-value <0.05 was considered significant.

- P-value $<0.001$ was considered as highly significant.

- P-value >0.05 was considered insignificant.

\section{RESULTS}

This prospective study was conducted at Gyn/Obs. Department, Beni-Suef General Hospital. It included 100 pregnant women diagnosed as placenta previa and subdivided into two main groups. Placenta Accreta Group ( $\mathrm{n}=51)$ which included patients had placenta previa with invasion and Placenta non Accreta Group $(n=49)$ that included patients with placenta previa but without invasion. Out of all the women in the final analysis, $51(51 \% \%)$ of them had histopathological confirmation of morbidly adherent placenta, and the remaining 49 (49\%) women served as the control group.

Cesarean hysterectomy was performed for all the Accreta Group patients (100\%) and was performed for 9 patients $(18 \%)$ in the non Accreta Group due to severe blood loss. No reported cases of maternal or neonatal mortality among cases enrolled in this study.

Out of the 100 patients, US suggested that 72 patients of them had placenta accreta while the other 28 cases had placenta non accreta. However, intra-operative assessment suggested that 56 patients had placenta accreta and only 44 cases had placenta non accreta. Moreover, histopathological assessment showed that 51 patients (out of 60 specimen) had placenta accreta and the other 9 cases were not Table 1.

Table (1): Results of used evaluation parameters in both study groups

\begin{tabular}{|l|c|c|c|}
\hline \multicolumn{1}{|c|}{ Parameter } & & Count & \% \\
\cline { 2 - 4 } & Accreta & 72 & $72.0 \%$ \\
\hline \multirow{2}{*}{$\begin{array}{l}\text { Intrasound evaluationerative } \\
\text { assessment }\end{array}$} & Non Accreta & 28 & $28.0 \%$ \\
\hline \multirow{2}{*}{$\begin{array}{l}\text { Histopathological } \\
\text { Pattern }\end{array}$} & Accreta & 56 & $56.0 \%$ \\
\cline { 2 - 4 } & Non Accreta & 44 & $44.0 \%$ \\
\hline
\end{tabular}

Mean age of patients enrolled in the study was 31.14 years, while the mean gestational age was 36 weeks and the mean number of CS is 2.59 Table 2. 
Table (2): Comparison between mean age, gestational age, parity, number of CS and SE among all patients

\begin{tabular}{|c|c|c|c|c|c|}
\hline & Mean & SD & Median & Minimum & Maximum \\
\hline Age & 31.14 & 5.01 & 32.00 & 20.00 & 40.00 \\
\hline GA & 36.11 & 2.06 & 36.00 & 28.00 & 39.00 \\
\hline Parity & 2.98 & 1.19 & 3.00 & 1.00 & 6.00 \\
\hline No. of CS & 2.59 & 1.09 & 2.00 & 1.00 & 5.00 \\
\hline No. of SE & 0.21 & 0.57 & 0.00 & 0.00 & 3.00 \\
\hline
\end{tabular}

There were no statistically significant differences regarding age, gestational age, parity, number of CS or Surgical evacuation by using ultrasound examination between both groups. On the other hand, the estimated blood loss was significantly higher in the accreta group compared to the non accreta group $(\mathbf{P}$ - value $=\mathbf{0 . 0 0 3})$ Table 3 .

Table (3): Comparison between cases of both groups regarding age, parity, gestational age, number of previous CS and surgical evacuation as well as estimated blood loss.

\begin{tabular}{|c|c|c|c|c|c|c|c|c|c|c|c|}
\hline & \multicolumn{5}{|c|}{ Accreta $(n=51)$} & \multicolumn{5}{|c|}{ Non accreta $(n=49)$} & \multirow[t]{2}{*}{$P$ value } \\
\hline & Mean & SD & Median & Minimum & Maximum & Mean & SD & Median & Minimum & Maximum & \\
\hline Age & 31.18 & 4.63 & 32.00 & 20.00 & 40.00 & 31.10 & 5.43 & 31.00 & 20.00 & 40.00 & .793 \\
\hline GA & 36.14 & 2.10 & 36.00 & 28.00 & 39.00 & 36.08 & 2.05 & 36.00 & 28.00 & 39.00 & .957 \\
\hline Parity & 2.98 & .99 & 3.00 & 1.00 & 5.00 & 2.98 & 1.38 & 3.00 & 1.00 & 6.00 & .946 \\
\hline No. of CS & 2.67 & .95 & 3.00 & 1.00 & 5.00 & 2.51 & 1.23 & 2.00 & 1.00 & 5.00 & .367 \\
\hline No. of SE & .22 & .61 & .00 & .00 & 3.00 & .20 & .54 & .00 & .00 & 3.00 & .781 \\
\hline $\begin{array}{l}\text { Estimated } \\
\text { blood loss } \\
(\mathrm{ml})\end{array}$ & 2531.37 & 786.76 & 62500.00 & 600.00 & 4000.00 & 2032.65 & 911.13 & 2000.00 & 700.00 & 4000.00 & .003 \\
\hline
\end{tabular}

There were no reported cases of ureteric injury in both groups. Bladder injury was significantly higher in the placenta accreta group $(n=10,19.6 \%)$ compared to the non accreta group $(n=3,6.1 \%)$ (p value 0.045). Postoperative ICU admissions were significantly higher in the accreta group $(n=29,56.9 \%)$ compared to the non accreta group $(\mathrm{n}=7,14.3 \%)$ (P value $<\mathbf{0 . 0 0 1})$. Also, the need for blood transfusion was significantly higher in the placenta accreta group (no.45, 88.2\%) compared to the non accreta group (no.20, 40.8\%) (P value $<\mathbf{0 . 0 0 1})$ Table 4.

Table (4): Comparison between cases of both groups regarding incidence of bladder and ureteric injury, post-operative ICU admission as well as Blood transfusion.

\begin{tabular}{|c|c|c|c|c|c|c|}
\hline \multirow{2}{*}{} & & \multicolumn{2}{|c|}{ Accreta $(\mathbf{n = 5 1})$} & \multicolumn{2}{l|}{ Non accreta $(\mathbf{n = 4 9})$} & P value \\
\cline { 2 - 6 } & & Count & $\mathbf{\%}$ & Count & $\mathbf{\%}$ & \\
\hline \multirow{2}{*}{ Bladder injury } & YES & $\mathbf{1 0}$ & $\mathbf{1 9 . 6 \%}$ & $\mathbf{3}$ & $\mathbf{6 . 1 \%}$ & $\mathbf{0 . 0 4 5}$ \\
\cline { 2 - 7 } & No & $\mathbf{4 1}$ & $\mathbf{8 0 . 4 \%}$ & $\mathbf{4 6}$ & $\mathbf{9 3 . 9 \%}$ & \\
\hline Ureteric Injury & No & $\mathbf{5 1}$ & $\mathbf{1 0 0 . 0 \%}$ & $\mathbf{4 9}$ & $\mathbf{1 0 0 . 0 \%}$ & --- \\
\hline \multirow{2}{*}{\begin{tabular}{c} 
Post Op. ICU admission \\
\cline { 2 - 6 }
\end{tabular}} & YES & $\mathbf{2 9}$ & $\mathbf{5 6 . 9 \%}$ & $\mathbf{7}$ & $\mathbf{1 4 . 3 \%}$ & $<\mathbf{0 . 0 0 1}$ \\
\cline { 2 - 7 } $\begin{array}{c}\text { Intra and post op blood } \\
\text { transfusion }\end{array}$ & No & $\mathbf{2 2}$ & $\mathbf{4 3 . 1 \%}$ & $\mathbf{4 2}$ & $\mathbf{8 5 . 7 \%}$ & \\
\cline { 2 - 7 } & yes & $\mathbf{4 5}$ & $\mathbf{8 8 . 2 \%}$ & $\mathbf{2 0}$ & $\mathbf{4 0 . 8 \%}$ & $<\mathbf{0 . 0 0 1}$ \\
\hline
\end{tabular}

Placenta previa was grading as below:

Grade 1 - Minor: Placenta extends to lower portion of the uterus but does not reach cervix.

Grade 2 - Marginal: Lower edge of placenta reaches cervix but does not cover it.

Grade 3 - Major: Placenta partially covers cervix.

Grade 4 - Major: Placenta completely covers cervix. 
Table 5 showed that placenta previa grade 4 was significantly higher in the placenta accreta group $(\mathrm{n}=42,82 \%)$ compared to the non accreta group $(n=29,59 \%)$ (p value $\mathbf{0 . 0 0 1}$ ). Gray scale, color Doppler criteria and diagnostic sensitivity, specificity, PPV and NPV of different methods of grayscale and color Doppler criteria in the studied group in correlation with histopathological pattern (60 patients had CS hysterectomy),

Table (5): Comparison between cases of the two groups regarding placenta grade.

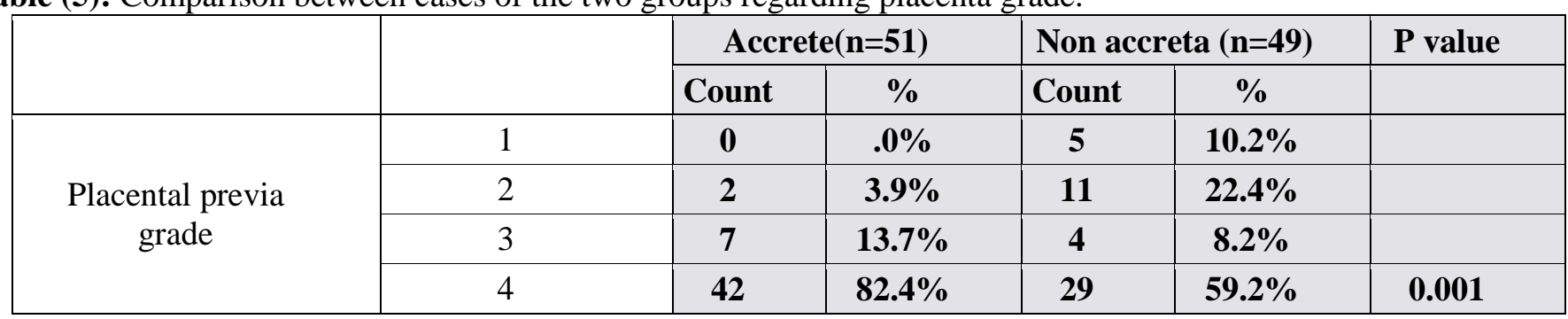

Our results showed highly statistically significant correlation between loss of clear zone and histopathological confirmation (P-value 0.001). In addition, the overall sensitivity, specificity, PPV, NPV and accuracy were 82.3\%, $77.7 \%, 95.5 \%, 43.7 \%, 81.6 \%$. This criterion showed high sensitivity with very high positive predictive value Table 6.

Table (6): Significance of loss of clear zone by ultrasound and histopathological pattern

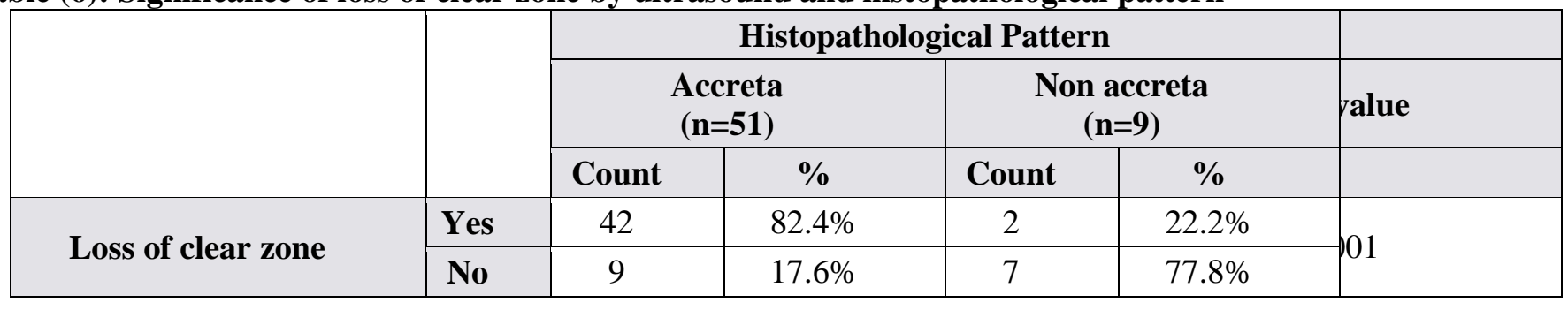

\begin{tabular}{|c|c|c|}
\hline Statistic & Value & 95\% CI \\
\hline Sensitivity & $82.35 \%$ & $69.13 \%$ to $91.60 \%$ \\
\hline Specificity & $77.78 \%$ & $39.99 \%$ to $97.19 \%$ \\
\hline Positive Predictive Value & $95.45 \%$ & $86.00 \%$ to $98.63 \%$ \\
\hline Negative Predictive Value & $43.75 \%$ & $28.10 \%$ to $60.75 \%$ \\
\hline Accuracy & $81.67 \%$ & $69.56 \%$ to $90.48 \%$ \\
\hline
\end{tabular}

Our results showed highly statistically significant correlation between the presence of abnormal lacunae and histopathological confirmation (P-value $<\mathbf{0 . 0 0 1}$ ). In addition, the overall sensitivity, specificity, PPV, NPV and accuracy were $90 \%, 100 \%, 100 \%, 64.2 \%, 91.6 \%$. This criterion showed very high sensitivity and specificity with very high positive predictive value and accuracy to become the most important criteria Table 7.

Table (7): Significance of the presence of abnormal lacunae by ultrasound and histopathological pattern

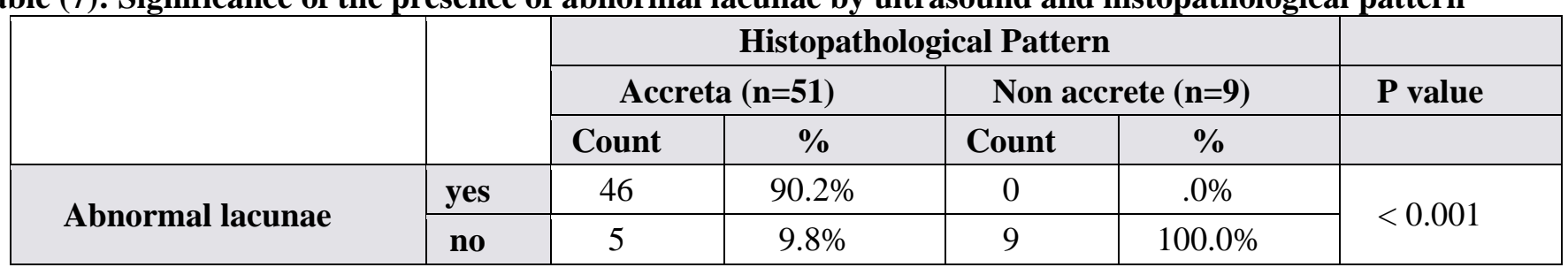

\begin{tabular}{|c|c|c|}
\hline Statistic & Value & 95\% CI \\
\hline Sensitivity & $90.20 \%$ & $78.59 \%$ to $96.74 \%$ \\
\hline Specificity & $100.00 \%$ & $66.37 \%$ to $100.00 \%$ \\
\hline Positive Predictive Value & $100.00 \%$ & \\
\hline Negative Predictive Value & $64.29 \%$ & $43.91 \%$ to $80.54 \%$ \\
\hline Accuracy & $91.67 \%$ & $81.61 \%$ to $97.24 \%$ \\
\hline
\end{tabular}

The present results showed no statistically significant correlation between the presence of bridging vessels and histopathological confirmation (P-value $\mathbf{= 0 . 1 3 4}$ ). In addition, the overall sensitivity, specificity, PPV, NPV and accuracy were $56.8 \%, 11.11 \%, 78.3 \%, 4.35 \%, 50 \%$ Table 8. 
Table (8): Significance of the presence of bridging vessels by ultrasound and histopathological Pattern.

\begin{tabular}{|c|c|c|c|c|c|c|}
\hline & & \multicolumn{4}{|c|}{ Histopathological Pattern } & \multirow{3}{*}{$P$ value } \\
\hline & & \multicolumn{2}{|c|}{$\begin{array}{l}\text { Accreta } \\
(n=51)\end{array}$} & \multicolumn{2}{|c|}{$\begin{array}{c}\text { Non accreta } \\
(\mathbf{n}=9)\end{array}$} & \\
\hline & & Count & $\%$ & Count & $\%$ & \\
\hline \multirow{2}{*}{ Bridging vessels } & yes & 29 & $56.9 \%$ & 8 & $88.9 \%$ & \multirow{2}{*}{0.134} \\
\hline & no & 22 & $43.1 \%$ & 1 & $11.1 \%$ & \\
\hline
\end{tabular}

\begin{tabular}{|c|c|c|}
\hline Statistic & Value & 95\% CI \\
\hline Sensitivity & $56.86 \%$ & $42.25 \%$ to $70.65 \%$ \\
\hline Specificity & $11.11 \%$ & $0.28 \%$ to $48.25 \%$ \\
\hline Positive Predictive Value & $78.38 \%$ & $72.22 \%$ to $83.48 \%$ \\
\hline Negative Predictive Value & $4.35 \%$ & $0.69 \%$ to $22.86 \%$ \\
\hline Accuracy & $50.00 \%$ & $36.81 \%$ to $63.19 \%$ \\
\hline
\end{tabular}

Our results showed statistically significant correlation between ultrasound evaluation and histopathological pattern (p value $=\mathbf{0 . 0 0 3}$ ). In addition, the overall sensitivity, specificity, PPV, NPV and accuracy were 96\%, 44.4\%, 90.7\%, $66.6 \%, 88.3 \%$ Table 9.

Table (9): Significance of Ultrasound evaluation and histopathological pattern

\begin{tabular}{|c|c|c|c|c|c|c|}
\hline & & \multicolumn{4}{|c|}{ Histopathological Pattern } & \multirow{3}{*}{ P value } \\
\hline & & \multicolumn{2}{|c|}{$\begin{array}{c}\text { Accreta } \\
(\mathrm{n}=51)\end{array}$} & \multicolumn{2}{|c|}{$\begin{array}{c}\text { Non accreta } \\
(\mathbf{n}=9)\end{array}$} & \\
\hline & & Count & $\%$ & Count & $\%$ & \\
\hline \multirow{2}{*}{ Ultrasound evaluation } & Accreta & 49 & $96.1 \%$ & 5 & $55.6 \%$ & \multirow{2}{*}{0.003} \\
\hline & not accreta & 2 & $3.9 \%$ & 4 & $44.4 \%$ & \\
\hline
\end{tabular}

\begin{tabular}{|c|c|c|}
\hline Statistic & Value & 95\% CI \\
\hline Sensitivity & $96.08 \%$ & $86.54 \%$ to $99.52 \%$ \\
\hline Specificity & $44.44 \%$ & $13.70 \%$ to $78.80 \%$ \\
\hline Positive Predictive Value & $90.74 \%$ & $84.49 \%$ to $94.63 \%$ \\
\hline Negative Predictive Value & $66.67 \%$ & $29.96 \%$ to $90.34 \%$ \\
\hline Accuracy & $88.33 \%$ & $77.43 \%$ to $95.18 \%$ \\
\hline
\end{tabular}

Our results showed no statistically significant correlation regarding mean values of Uterine artery Doppler PI and RI between cases of both groups by histopathological examination ( $p$ value $=.078 \& 0.58$ respectively) Table 10.

Table (10): Comparison between cases of the two groups regarding mean values of uterine artery Doppler PI and RI in correlation with Histopathological pattern.

\begin{tabular}{|c|c|c|c|c|c|c|c|c|c|c|c|}
\hline & \multicolumn{10}{|c|}{ Histopathological Pattern } & \multirow{3}{*}{$P$ value } \\
\hline & \multicolumn{5}{|c|}{ Accretea $(n=51)$} & \multicolumn{5}{|c|}{ Non accreta $(\mathrm{n}=9)$} & \\
\hline & Mean & SD & Median & Minimum & Maximum & Mean & SD & Median & Minimum & Maximum & \\
\hline $\begin{array}{c}\text { Uterine } \\
\text { artery } \\
\text { doppler } \\
\text { PI } \\
\end{array}$ & 0.81 & 0.21 & 0.81 & 0.40 & 1.50 & 0.91 & 0.22 & 1.03 & 0.52 & 1.12 & 0.078 \\
\hline $\begin{array}{c}\text { Uterine } \\
\text { artery } \\
\text { doppler } \\
\text { RI }\end{array}$ & 0.54 & 0.12 & 0.52 & 0.32 & 0.80 & 0.58 & 0.17 & 0.52 & 0.39 & 0.81 & 0.583 \\
\hline
\end{tabular}

The present results showed no statistically significant correlation regarding mean values of uterine artery Doppler PI and RI between cases of both groups by clinical evaluation ( $\mathbf{p}$ values $=\mathbf{0 . 3 4 1 ,} \mathbf{0 . 9 5 3}$ respectively) Table 11 
Table (11): Comparison between cases of both groups regarding mean values of uterine artery Doppler PI and RI in correlation with operative findings.

\begin{tabular}{|c|r|r|r|r|r|r|r|r|r|r|r|}
\hline & \multicolumn{7}{c|}{ Operative findings } & \multicolumn{3}{c|}{ Non accreta (n=44) } & P value \\
\hline & Mean & SD & Median & Minimum & Maximum & Mean & SD & Median & Minimum & Maximum \\
\hline $\begin{array}{c}\text { uterine artery } \\
\text { doppler PI }\end{array}$ & 0.82 & 0.20 & 0.82 & 0.40 & 1.50 & .85 & 0.21 & 0.84 & 0.42 & 1.20 & 0.341 \\
\hline $\begin{array}{c}\text { uterine artery } \\
\text { doppler RI }\end{array}$ & 0.55 & 0.13 & 0.52 & 0.32 & 0.80 & 0.56 & 0.17 & 0.52 & 0.31 & 0.90 & 0.953 \\
\hline
\end{tabular}

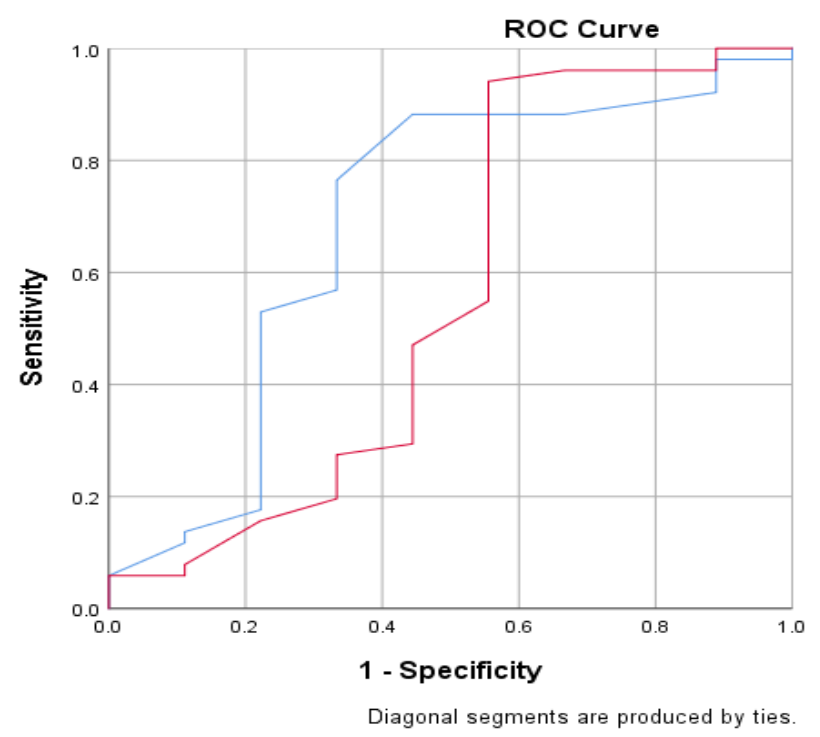

\begin{tabular}{|l|c|c|c|c|}
\hline \multirow{2}{*}{ Test Result Variable(s) } & \multirow{2}{*}{$\begin{array}{c}\text { Area Under } \\
\text { the Curve }\end{array}$} & \multirow{2}{*}{ P value } & \multicolumn{2}{|c|}{$\mathbf{9 5 \% \text { Confidence Interval }}$} \\
\cline { 4 - 5 } & 0.685 & 0.078 & Lower Bound & Upper Bound \\
\hline Uterine artery doppler PI & 0.558 & 0.583 & 0.464 & 0.906 \\
\hline Uterine artery doppler RI & 0.599 & 0.816 \\
\hline
\end{tabular}

Figure (1): Receiver operating characteristic curve (ROC) curve for prediction of accrete by histopathology using Doppler measures.

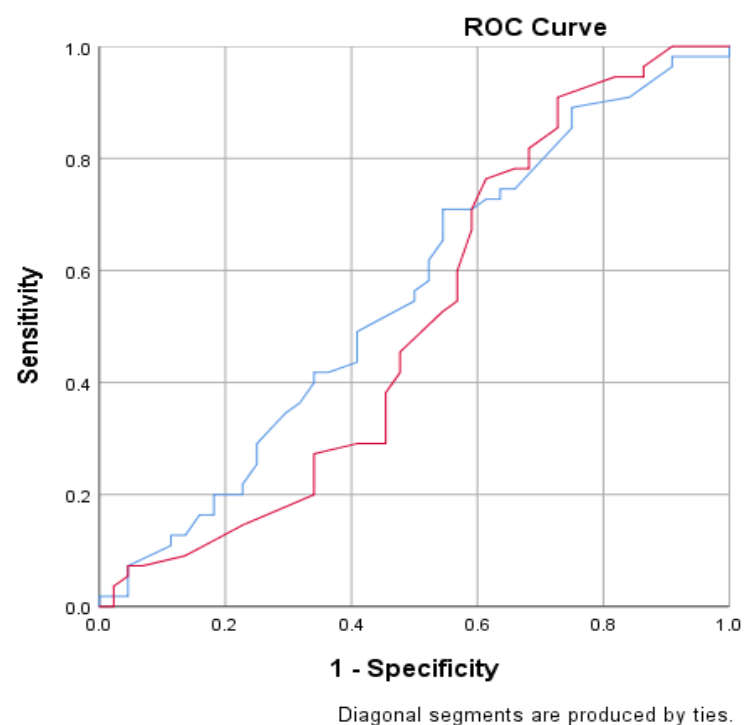

\begin{tabular}{|c|c|c|c|c|}
\hline \multirow{2}{*}{ Test Result Variable(s) } & \multirow{2}{*}{$\begin{array}{c}\text { Area Under } \\
\text { the Curve }\end{array}$} & \multirow{2}{*}{ P value } & \multicolumn{2}{|c|}{ 95\% Confidence Interval } \\
\cline { 4 - 5 } & 0.556 & 0.342 & Lower Bound & Upper Bound \\
\hline Uterine artery doppler PI & 0.511 & 0.855 & 0.440 & 0.672 \\
\hline Uterine artery doppler RI & 0.390 & 0.632 \\
\hline
\end{tabular}

Figure (2): ROC curve for prediction of accrete by operative findings using Doppler measures. 


\section{DISCUSSION}

The aim of the study was to assess the efficacy of ultrasound (2D gray scale and Doppler study) via trans-abdominal and/or trans-vaginal approach in the prediction of the operative findings and possible associated co-morbidities, thus to optimize and individualize preoperative preparations and set the operative plan among placenta accreta cases, thus improving the post-operative outcomes.

Also, the study of uterine artery Doppler as a new modality to help assess the possibility of invasion of placenta by comparing Doppler values of placenta accreta with placenta non accreta.

\section{Regarding the presence of abnormal placental lacunae:}

This study showed sensitivity, specificity, PPV, NPV and accuracy were $90.2 \%, 100 \%, 100 \%, 64.2 \%$ and $91.6 \%$ respectively in correlation with histopathological assessment. In addition our study showed sensitivity, specificity, PPV, NPV and accuracy were $83.93 \%, 81.8 \%, 85.4 \%, 80 \%$ and $83 \%$ respectively in correlation with intraoperative assessment.

Highly statistical difference was noticed between the two groups where $90 \%$ of cases with histopathological confirmation had abnormal lacunae among the accreta group vs $0 \%$ in the non accreta group.

Our study agreed with Maged and his colleagues ${ }^{(9)}$ who found that the presence of abnormal lacunae sensitivity 93\%, PPV80.82\%, NPV 85.19\% while accuracy reached $82.00 \%$.

Pilloni et al. ${ }^{(10)}$ suggested the presence of abnormal lacunae with $94.6 \%$ specificity and with $48.6 \%$ sensitivity.

Whereas Cali et al. (11) found that presence of abnormal lacunae showed sensitivity $73.0 \%$, and specificity $86.7 \%$.

Yang et al. ${ }^{(12)}$ who found that the presence of abnormal lacunae showed sensitivity $86.9 \%$, specificity $78.6 \%$, PPV 76.9 and NPV $88 \%$. In a recent systematic review, the overall pooled sensitivity and specificity from 13 studies of lacunear spaces diagnosing MAP was $77 \%$ and $95 \%$ respectively, with an overall diagnostic accuracy of 88\% D'Antonio et al. ${ }^{\text {(13) }}$. Abnormal placental lacunae have the highest accuracy among other criteria of US findings with high sensitivity and specificity.

Regarding loss of the retroplacental clear zone:

This study showed that sensitivity, specificity, PPV ,NPV and accuracy were $82.35 \%, 77.7 \%$, $95.4 \%, 43.7 \%$ and $81.6 \%$ in correlation with histopathological assessment, in addition our study showed sensitivity, specificity, PPV, NPV and accuracy were $78.5 \%, 88.6 \%, 89.8 \%, 76.4 \%$ and $83 \%$ in correlation with intra-operative assessment.
Maged et al. ${ }^{(9)}$ suggested the loss of retro-placental clear zone to have $87.3 \%$ sensitivity, $89.1 \%$ specificity, 93\% PPV, $80 \%$ NPV and $88 \%$ accuracy which agreed with our study.

Pilloni et al. ${ }^{(10)}$ suggested $81 \%$ sensitivity and $97 \%$ specificity to the retro placental zone disruption. In a recent systematic review, the overall pooled sensitivity and specificity from 13 studies of loss of retroplacental clear zone diagnosing MAP was 66\% and $95 \%$ respectively.

Wong et al. ${ }^{\left({ }^{14}\right)}$ found absence of the clear space in 37 (65\%) of women without placenta accreta and in $100 \%$ of those women with it. Hence, it is sensitive but not specific.

The primary use of the clear space appears to be that its presence effectively excludes placenta accreta because it has a high negative predictive value (NPV), in contrary. Finberg and Williams ${ }^{(15)}$ stated that the loss of the retroplacental clear zone accounts for most of False Positive results and the criterion should not be used by itself to make the diagnosis.

Regarding the presence of placental bulge:

This study showed that the sensitivity, specificity, PPV, NPV and accuracy were $47.06 \%, 44 \%, 82.6 \%$, $12.9 \%$ and $46.6 \%$ respectively in correlation with histopathological assessment. In addition, our study showed sensitivity, specificity, PPV, NPV and accuracy were $46 \%, 75 \%, 70 \%, 52 \%$ and 59\% respectively in correlation with intra-operative assessment.

Our study agreed with Comstock ${ }^{(16)}$ who stated that placental bulge isn't sensitive and agreed with him in being specific where he found it a specific sign.

Regarding interruption of the bladder wall:

This study showed that the sensitivity, specificity, PPV, NPV and accuracy were $68.6 \%, 44.4 \%, 87.5 \%$, $20 \%$ and $65 \%$ respectively in correlation with histopathological assessment. In addition, the present study showed sensitivity, specificity, PPV, NPV and accuracy were $64 \%, 77 \%, 78 \%, 62 \%$ and $70 \%$ respectively in correlation with intra-operative assessment.

Pilloni et al. ${ }^{(10)}$ suggested $40 \%$ sensitivity and $98 \%$ specificity to disruption of serosal-bladder interface.

Lax et al. ${ }^{(17)}$ suggested $21 \%$ sensitivity and $100 \%$ specificity. In a previously systematic review, the overall pooled sensitivity and specificity from 9 studies of abnormalities of utero-bladder interface diagnosing MAP was $49 \%$ and $99 \%$ respectively ${ }^{(\mathbf{1 3})}$.

Cali et al. ${ }^{(11)}$ suggested that this criterion showed sensitivity $70 \%$, specificity $100 \%$, PPV $100 \%$, NPV $100 \%$. Unlike Comstock (16), whose finding had sensitivity of 20\%, PPV $75 \%$, and Wong et al. ${ }^{(14)}$ whose sensitivity reached $11 \%$ and specificity $100 \%$.

The interruption of this line is a result of increased vascularity in this space, as they showed using color Doppler; it does not signify invasion of the bladder 
because interruption can be seen in placenta accrete (13).

Our results did not agree with most studies because it showed low specificity unlike most studies which have high specificity. These differences may be due to intra-observer variability.

Regarding the uterovesical hypervascualrity using Color Doppler Flow

This study showed that sensitivity, specificity, PPV, NPV and accuracy were $82 \%, 33 \%, 87 \%, 25 \%$ and $75 \%$ respectively in correlation with histopathological assessment. In addition, our study showed Sensitivity, specificity, PPV, NPV and accuracy were $83 \%, 70 \%, 78 \%, 77 \%$ and $78 \%$ respectively in correlation with intra-operative assessment.

Our study did not agree with Pilloni et al. ${ }^{(10)}$ where it showed $10.8 \%$ sensitivity and $98 \%$ specificity.

Our study agreed with a recent systematic review, the overall pooled sensitivity and specificity from 12 studies of abnormalities of color Doppler diagnosing MAP was $90 \%$ and $89 \%$ respectively ${ }^{(13)}$.

Our study agreed with Cali et al. ${ }^{(11)}$ where it showed sensitivity 90\%, specificity 100\%, PPV 100\%, NPV 97\%.

Regarding uterine artery Doppler values:

The present results showed no statistically significant correlation regarding mean values of uterine artery Doppler PI and RI between cases of placenta accreta and non accreta $(\mathrm{p}$ value $=.078 \&$ 0.58 respectively) in correlation with histopathological assessment. Our results showed no statistically significant correlation regarding mean values of uterine artery Doppler PI and RI between cases of placenta accreta and placenta non accreta ( $p$ values $=0.341,0.953$ respectively) in correlation with intra-operative assessment.

A study was held by Cho et al. ${ }^{(18)}$ reported that the mean uterine artery PI was significantly lower in the placenta accreta group compared to placenta previa group and this disagreed with the present study as we found no significant association.

Our study had some limitations as uterine artery Doppler velocimetry and placental morphology were performed by different operators during the study period. However, all operators were well-trained experts who fully understood the protocol before starting the examination, but a bias between operators may still have existed. A well-organized prospective study will be necessary to address this issue. Yet what we conclude and address firmly is that planning which could be aided by such simple tools could easily decline morbidity and mortality both on maternal and fetal sides.

\section{CONCLUSION}

Different ultrasound criteria can be used for accurate diagnosis of placenta accreta. They include loss of retroplacental clear zone, presence of abnormal placental lacunae, myometrial thinning and utero-vesical hypervascularity. On the other hand, both loss of retroplacental clear zone, abnormal placental lacunae can predict which patient will mostly have CS hysterectomy.

No statistically significant value of uterine artery Doppler indices was observed during the present study when comparing both study groups.

\section{REFERENCES}

1. Clark SL, Koonings PP, Phelan JP (1985): Placenta previa/accreta and prior cesarean section. Obstet Gynecol., 66: 89-92

2. Wortman AC, Alexander JM (2013): Placenta accreta, increta, and percreta. Obstet Gynecol Clin North Am., 40(1):137-154

3. Angstmann T, Gard G, Harrington T et al. (2013) Surgical management of placenta accreta: a cohort series and suggested approach. Am J Obstet Gynecol., 6:181197.

4. American College of Obstetricians and Gynecologists (2012): Placenta accreta committee opinion no. 529. Obstet Gynecol., 120:207-211.

5. Warshak CR, Ramos GA, Eskander $R$ et al. (2010): Effect of predelivery diagnosis in 99 consecutive cases of placenta accreta. Obstet Gynecol., 115(1):65-69.

6. Lerner JP, Deane S, Timor-Tritsch IE (1995): Characterization of placenta accreta using transvaginal sonography and color Doppler imaging ultrasound. Obstet Gynecol., 5: 198-203.

7. Sunna E, Ziadeh S (1999): Transvaginal and transabdominal ultrasound for the diagnosis of placenta praevia. J Obstet Gynaecol., 19(2):152-4.

8. Collins SL, Ashcroft A, Braun T et al. (2016): European Working Group on abnormally invasive Placenta (EW-AIP). Ultrasoun Obstet Gynecol., 47(3):271-5.

9. Maged AM, Abdelaal H, Salah E et al.(2018): Prevalence and diagnostic accuracy of Doppler ultrasound of placenta accreta in Egypt. J Matern Fetal Neonatal Med.,31(7):933939.

10. Pilloni E, Alemanno MG, Gaglioti P et al. (2016): Accuracy of ultrasound in antenatal diagnosis of placental attachment disorders. Ultrasound Obstet Gynecol., 47: 302-307

11. Calì G, Giambanco L, Puccio G et al. (2013): Morbidly adherent placenta: Evaluation of ultrasound diagnostic criteria and differentiation of placenta accreta from percreta, Ultrasound Obstet Gynecol., 41:406- 12.

12. Yang JI, Lim YK, Kim HS et al. (2006): Sonographic findings of placental lacunae and the prediction of adherent placenta in women with placenta previa totalis and prior Cesarean section, Ultrasound Obest Gynecol., 28(2):178182.

13. D'Antonio F, Iacovella C, Bhide A (2013): Prenatal identification of invasive placentation using ultrasound: 
ejhm.journals.ekb.eg

systematic review and meta-analysis. Ultrasound Obstet Gynecol., 42: 509-517.

14. Wong HS, Cheung YK, Williams E (2012): Antenatal ultrasound assessment of placental/myometrial involvement in morbidly adherent placenta. Obstet Gynaecol., 52: 67-72.

15. Finberg HJ, Williams JW (1992): Placenta accreta: prospective sonographic diagnosis in patients with placenta previa and prior cesarean section. J.Ultrasound Med., 11:333-43.
16. Comstock CH (2011): The antenatal diagnosis of placental attachment disorders. Curr Opin Obstet Gynecol., 23(2):117-22.

17. Lax A, Prince MR, Mennit KW et al. (2007): The value of specific MRI features in the 123 evaluation of suspected placental invasion. Magnetic Resonance Imaging, 9: 8793.

18. Cho HY, Hwang HS, Jung I et al. (2015): Diagnosis of placenta accreta by uterine artery doppler velocimetry in patients with placenta previa. American Institute of Ultrasound in Medicine, 34 :1571- 1575. 